\title{
THE EFFECTS OF THE SEAT CUSHION CONTOUR AND THE SITTING POSTURE ON SURFACE PRESSURE DISTRIBUTION AND COMFORT DURING SEATED WORK
}

\author{
WENHUA LI, RONG MO, SUIHUAI YU, JIANJIE CHU, YUKUN HU, and LONG WANG \\ Northwestern Polytechnical University, Xi'an, China \\ Department of Industrial Design
}

\begin{abstract}
Objectives: The purpose of this paper is to investigate the effects of the seat cushion contour and the sitting posture on the seat pan interface pressure distribution and subjective comfort perception. Material and Methods: Overall, 16 volunteers typed a text passage on a laptop while seated, by assuming 3 kinds of common sitting postures (forward, relaxed and upright) in 4 seat cushion configurations: chair only, and chair with 1 of 3 supplementary cushions. Pressure data and cushion comfort ratings were collected in the experiment. Results: It was found that the sitting posture and the seat cushion contour had different impacts on surface pressure. The seat cushion contour had an impact on pressure parameters and pressure distribution on the seat pan, while the sitting posture affected the location of peak pressure on the seat pan. The correlation analysis revealed that the subjective comfort rating was significantly correlated with average pressure (AP) and mean peak pressure (MPP). Conclusions: The conclusion was that the cushion contour had a greater effect on seat pan interface pressure parameters than the sitting posture. Notably, AP and MPP can be indicators for assessing seat cushion comfort in a short-term perspective. Int J Occup Med Environ Health. 2020;33(5):675-89
\end{abstract}

Key words:

comfort, seat cushion, seat cushion contour, surface pressure distribution, office chair, pressure measurement

\section{INTRODUCTION}

In a modern society, many occupations require workers to use computers to do their jobs with workstations in the office environment. The sitting posture becomes the most common working posture in today's workplace, and $>75 \%$ of employees in industrial countries do their jobs while seated [1]. It has been shown that the design of an office chair can strongly influence the sitting conditions for the user. The seat pan and backrest cushion properties matter a lot for the sitting comfort. Therefore, optimizing both the workstation and chair design has constantly been the ergonomists' goal.

When taking standing as a neutral posture, the sitting posture is characterized by a posterior pelvic rotation position [2]. This position forces the lumbar spine to endure more loading, which can over time lead to chronic back issues [3]. The optimal occupational sitting postures and sitting behaviors have been extensively discussed in literature. Both researchers and clinicians have carried out extensive experimental research and clinical studies in recent

Funding: this research was supported by the Ministry of Industry and Information Technology (project No. MJ-2015-F-018 entitled "The special research on civil aircraft: Key technology research on civil aircraft cabin design and comfort evaluation," project manager: Bingchen Gou) and by Northwestern Polytechnical University (project No. B13044 entitled "Project 111," project manager: Suihuai Yu).

Received: December 12, 2019. Accepted: June 4, 2020.

Corresponding author: Wenhua Li, Northwestern Polytechnical University, Department of Industrial Design, Youyi Road (West) 127, 710072 Xi'an, China (e-mail: iliwenhua@mail.nwpu.edu.cn). 
years. There exists a consensus that an incorrect sitting posture contributes to many disorders in the cervical and lumbar spine. However, there is no optimal sitting posture, according to a review paper released by Pynt et al. [4]. The concept of "dynamic sitting" is gradually becoming a common method of preventing and relieving the musculoskeletal disorders related to the sedentary lifestyle. Dynamic chairs are provided with certain swinging mechanisms, and these systems allow for a greater variation in the inclination angles of the seat [5]. The 2 most frequently adopted sitting positions were the upright and forward inclined sitting positions during work in front of the computer. A video display terminal (VDT) guideline released by Waseda University in 1995 for operators using portable PCs reported that there are 3 common sitting postures - upright, bent forward and bent backward (reclining). More recent research has found that $>70 \%$ of VDT operators work with slouched shoulders without using backrests. These 3 common sitting postures in the office environment, i.e., the forward leaning posture, the upright posture, as well as the reclined posture, have been studied [6,7]. Numerous researchers have voiced concerns about the effects of the sitting posture on the muscle activity and spinal posture $[8,9]$. These studies have shown that postural variables affect internal physiological conditions, subjective comfort ratings and productivity [10].

Several studies have suggested that the shape and firmness of the surface at the seat interface can affect the perception of sitting comfort [11]. Most research studies focus on wheelchair users, like patients with spinal cord injuries, who cannot move their body freely and stay on the chair for a long time. The characteristics of different types of cushions have been compared by various teams, including the filling material [12,13], cushion thickness [14], and the recline angle [15]. However, to the best of the authors' knowledge, there is still a lack of knowledge concerning the optimal office seat cushion properties and geometry to contribute to pressure relief on the buttock during extended sitting periods. Nowadays, there are several kinds of supplementary seat cushions on the market, which were declared to be beneficial to relieve low back pain (LBP), and to reduce pressure on the coccyx, tail bone and hip bones. From the product market perspective, with a large selection of consumer products in stores, there is a need to establish seat cushion design and selection criteria based on relationships between comfort, pressure, posture, and anthropometrics.

Seat comfort has been investigated in the context of the characteristics of an office chair, an automobile seat, a mobile machinery seat, and an aircraft seat. Through the experiment, it was concluded that chair design had the greatest effect on the pressure distribution on the seat pan, followed by participant-specific effects and, finally, postural treatments (including different backrest angles and the use of armrests) [16]. The seat pan and backrest cushion properties play a decisive role in the chair-user interaction, including backrest inclination angles, seat pan inclination, supplementary backrest thickness, and cushion filling material. Research has found an almost 50\% reduction in the mean seat pressure on a wheelchair due to a different cushion being used [17]. Among the chair characteristics related to seating and chair design, the cushion is a focal point. It is also known that the seat shape is important when selecting or designing a support surface for office chairs, wheelchairs or automobile seats. Tasker et al. [18] compared 2 kinds of cushion shapes with a flat baseline surface and confirmed that custom-contoured shapes effectively reduced pressure ulcers. However, the effect of different levels of shape contouring has not been adequately studied yet.

Some studies have proven that a good body pressure distribution is related to comfort [19]. A well-designed chair should make body pressure distribution have a gradient from the ischial tuberosities which have the highest stress. A growing body of literature has investigated the effects of the sitting posture and chair design on the comfort and physiological response during seated work. It remains unclear how the combined risks of the sitting posture and 
Table 1. Demographic data on the participants of the study conducted in the ergonomics lab at the Department of Industrial Design, Northwestern Polytechnical University, Xi'an, China, June 6-11, 2018

\begin{tabular}{|c|c|c|c|c|}
\hline \multirow{3}{*}{ Variable } & \multicolumn{4}{|c|}{$\begin{array}{l}\text { Participants } \\
\quad(\mathrm{N}=16)\end{array}$} \\
\hline & \multicolumn{2}{|c|}{$\begin{array}{l}\text { males } \\
(\mathrm{N}=8)\end{array}$} & \multicolumn{2}{|c|}{$\begin{array}{l}\text { females } \\
(\mathrm{N}=8)\end{array}$} \\
\hline & $\mathrm{M} \pm \mathrm{SD}$ & $\min .-\max$ & $\mathrm{M} \pm \mathrm{SD}$ & $\min .-\max$ \\
\hline Age [years] & $26 \pm 4.17$ & $23-29$ & $31 \pm 6.03$ & $24-41$ \\
\hline Body mass $[\mathrm{kg}]$ & $78.5 \pm 11.17$ & $66-94$ & $53.50 \pm 6.68$ & $45-65$ \\
\hline Height $[\mathrm{m}]$ & $1.77 \pm 0.05$ & $1.70-1.85$ & $1.61 \pm 4.60$ & $1.53-1.68$ \\
\hline Body mass index $\left[\mathrm{kg} / \mathrm{m}^{2}\right]$ & $24.97 \pm 3.29$ & 22.49-30.69 & $20.78 \pm 2.87$ & $17.80-24.77$ \\
\hline
\end{tabular}

seat cushion contour might present over time, whether they can aid in spinal unloading or form a good body pressure distribution.

The overall aim of the present study was to investigate the influence of both the seat cushion contour and the sitting posture on body pressure distribution and the subjective degree of comfort, and to find a better configuration among the alternative contours for people working with a PC.

The main research questions to be answered in this study are:

- What is the effect of a seat cushion with a distinctive contour, compared to a regular cushion, on pressure parameters? Pressure parameters include average pressure (AP), mean peak pressure (MPP), mean contact area (MCA) and maximum pressure gradient (MaxPG).

- Seat cushions with distinctive contours have a larger superficial area than the common flat seat cushion. Does the seat cushion with a distinctive contour have a bigger contact area than the regular cushion?

- Does the seat cushion with a distinctive contour offer a better comfort degree than the regular cushion?

- What is the effect of sitting posture on pressure parameters?

- Is there a relationship between the subjective comfort perception and pressure parameters?
The hypotheses for this study were of a 2-fold nature. First, the authors hypothesized that the seat cushion contour would influence the pressure distribution of the seat pan surface. Second, they hypothesized that the body surface pressure could be an effective indicator to differentiate seat cushions.

\section{MATERIAL AND METHODS}

\section{Subjects}

Overall, 16 adult volunteers (8 males and 8 females) recruited from Northwestern Polytechnical University (NPU) participated in this experiment. All the subjects were asymptomatic, had not experienced any LBP in the past 2 years, and had no previous spinal surgery. All of them were computer-using workers and usually sat for nearly $8 \mathrm{~h}$ on their workdays. The subjects' demographic data are shown in Table 1. All the subjects signed written consent forms before participating in the study.

\section{Experimental design and protocol}

This study utilized a within-subjects design. The independent variables included the chair seat pan condition (no supplementary cushion, supplementary seat cushion 1, 2 and 3) and 3 sitting postures (forward, relaxed, upright) (Figure 1). The dependent variables were body pressure distribution and the subjective comfort perception for the cushions. All 
a)

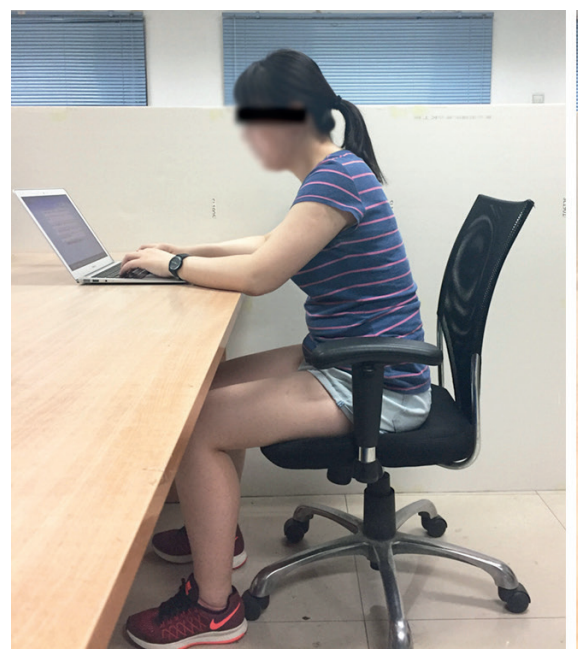

b)

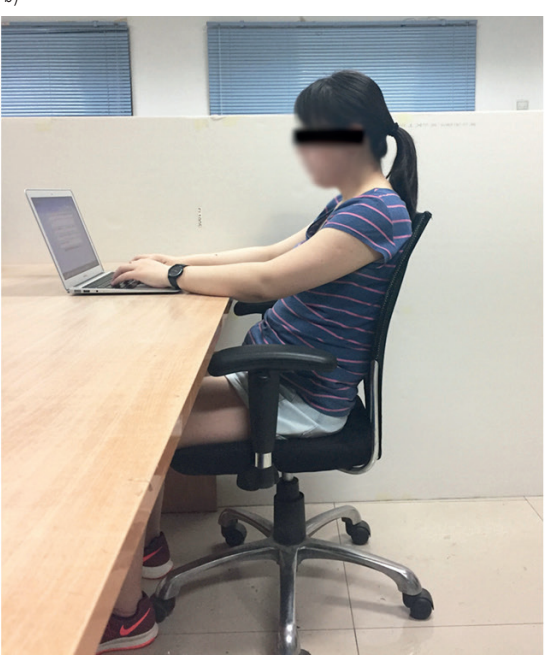

c)

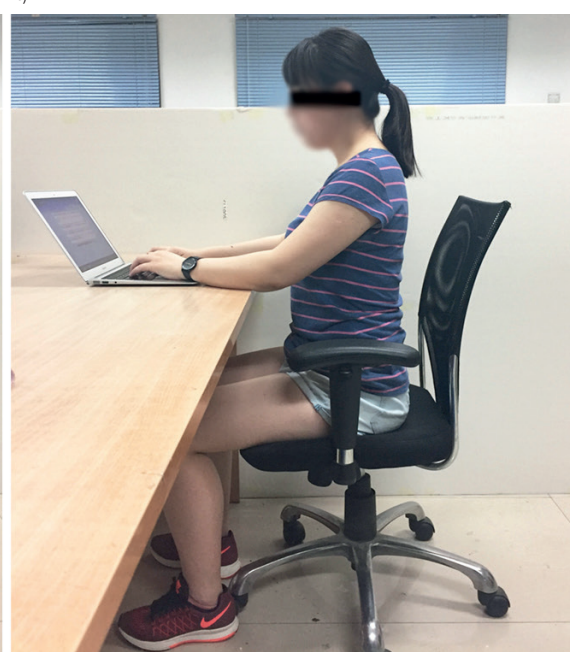

Figure 1. Three sitting postures: a) P1 - forward, b) P2 - relaxed, c) P3 - upright, used in the study conducted on 16 volunteers in the ergonomics lab at the Department of Industrial Design, Northwestern Polytechnical University, Xi'an, China, June 6-11, 2018

the participants completed the same protocol (Figure 2). The whole session consisted of 4 trials; every trial tested a seat pan condition. The first trial used the chair without a supplementary cushion (referred to as $\mathrm{C} 0$ ). The subsequent 3 trials randomly chose 1 of the cushions as a seat pan condition $(\mathrm{C} 1$, $\mathrm{C} 2$ and $\mathrm{C} 3$, respectively). During every trial, the participants were required to sit, by assuming 3 sitting postures, to perform the typing task. There were 1-min breaks and 5-min breaks, respectively, between 2 sitting postures of 1 trial, and between 2 trials. After 1 trial had finished, the subject was asked to fill in the seat cushion comfort rating questionnaire.

\section{Measurements}

Body pressure measurement system

Interface pressure data were recorded by Tekscan (South Boston, MA, USA) (Figure 3). This system included a pressure sensors mat (5330 CONFORMat ${ }^{\mathrm{TM}}$ ) and software; it was used to measure the pressure distribution of different body regions. Each pressure mat consisted of $1024(32 \times 32)$ thin $(1.78 \mathrm{~mm})$ resistive sensors that could easily conform to the contour of the seat and measure up to $250 \mathrm{~mm} \mathrm{Hg}$ (5 PSI). Each mat had the active area of $471.4 \times 471.4 \mathrm{~mm}$, and the sensor pitch was $14.73 \mathrm{~mm}$

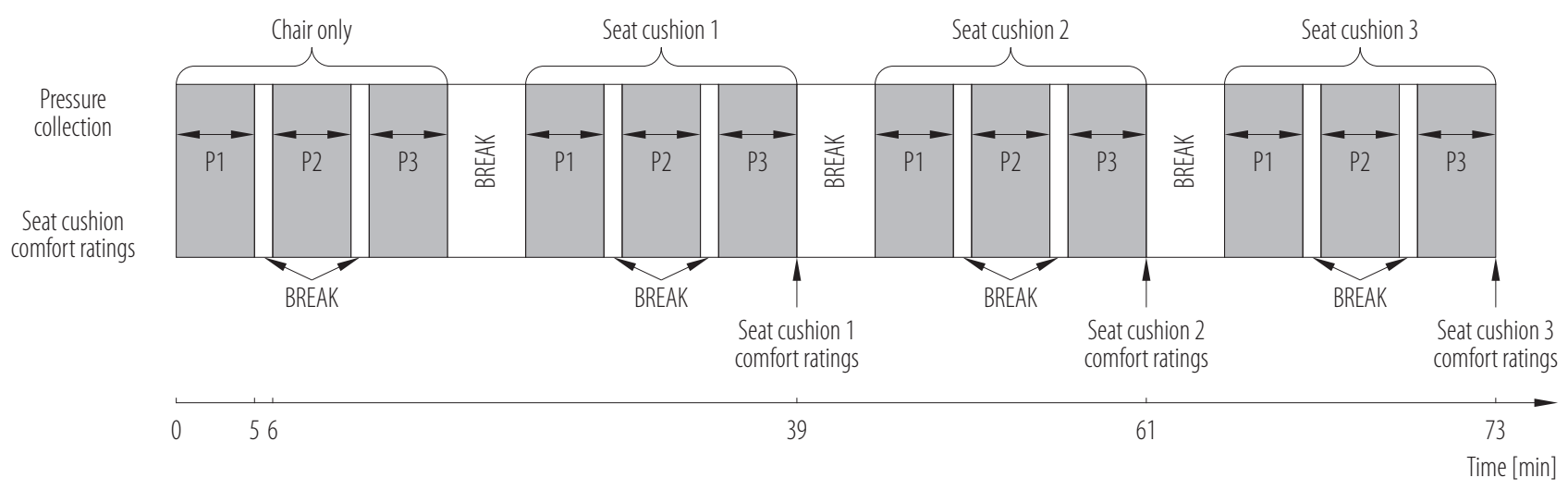

Figure 2. The collection protocol employed in the study conducted on 16 volunteers in the ergonomics lab at the Department of Industrial Design, Northwestern Polytechnical University, Xi'an, China, June 6-11, 2018 
$\left(0.5 \mathrm{sensor} / \mathrm{cm}^{2}\right)$. Pressure values were recorded at $1 \mathrm{~Hz}$ in the software matched with the pressure mat. This sampling rate was considered accurate enough, as the frequency of postural changes and resultant pressure changes were not observed to occur within an order of magnitude of the sampling rate.

\section{Workstation and seat cushion}

The height of the workstation and the chair in this experiment were adjustable. The chair used in the experiment had a 5-point base, a hydraulic/pneumatic main support cylinder, a flat seat pan, a backrest and a pair of armrests (Figure 3). The authors collected seat cushion information online and searched through the purchasing records of ecommerce platforms (Amazon, Alibaba), following which the top 3 seat cushions for office chairs were selected and used in the study. Three supplementary seat cushions used in this study had the distinctive contoured shapes, and were made of polyurethane foam with an outer layer of cloth material (Figure 4). The dimensions of the 3 cushions were roughly $46 \times 40 \times 6 \mathrm{~cm}^{3}$.

\section{Subjective comfort ratings for cushions}

The seat cushion comfort degree was rated numerically at the end of every seat cushion condition using the visual analog scale (Figure 5). This comfort rating method is an objectification tool to convert human sensation into a quantifiable value. The seat cushion comfort rating is an overall evaluation, with evaluation factors mainly referring to the support of the cushion and skin pressure. As shown in Figure 5, in this experiment, the comfort rating of an office chair without a supplementary cushion was regarded as a benchmark and was denoted as "0." The length of the line was $10 \mathrm{~cm}$, the left half was marked as "discomfort" and the right half was marked as "comfort." The left endpoint marked as "intolerable" stands for -5 and the right endpoint, "considerable," means 5 . This scale is a bipolar continuum and allows the allocation

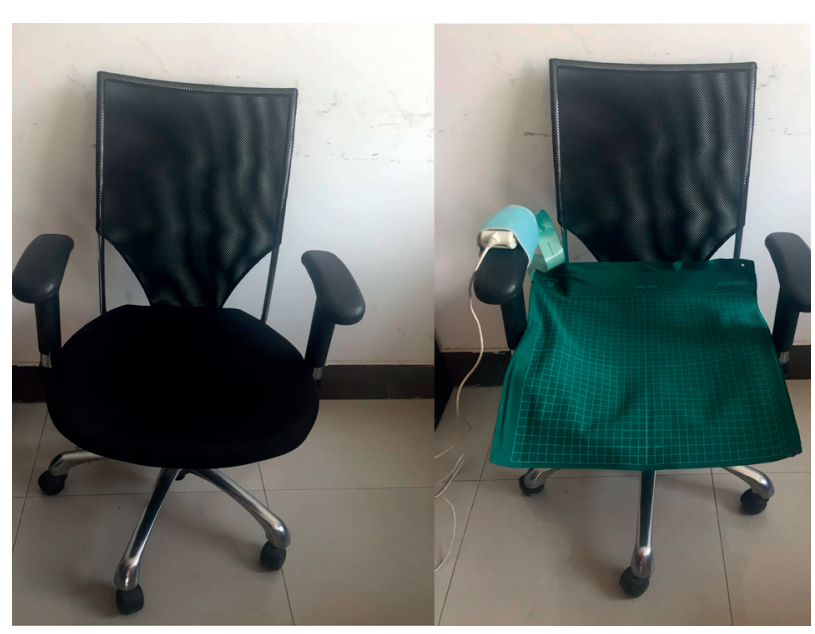

Figure 3. The office chair used in the experiment, along with the pressure mat, in the study conducted on 16 volunteers in the ergonomics lab at the Department of Industrial Design, Northwestern Polytechnical University, Xi'an, China, Xi'an, China, June 6-11, 2018

of intermediate values. The participants were informed to rate the comfort of the seat cushion by making a cross on the line, with the comfort degree representing a comparative value with the original chair without a supplementary cushion. The distance between the cross in the line with the middle point can be converted to the corresponding comfort value ranging $-5-5$. Using the example shown in Figure 5, the red cross is located on the right, and the distance is $3.5 \mathrm{~cm}$, so the comfort degree is 3.5 .

\section{Experimental procedure}

This experiment was conducted in the ergonomics lab at the Department of Industrial Design on June 6-11, 2018. Before commencing the experiment, the subjects were given instructions on the experimental procedures and the visual analog scale. They were asked to do as the experimenter required. First, the subjects adjusted the workstation and the chair to the suitable height. The seat cushions were covered with a white cloth during the experiment. A laptop was placed $10 \mathrm{~cm}$ from the edge of the workstation. After the calibration of the pressure mat on the seat pan was completed by the experimenter, the subjects were 
a)

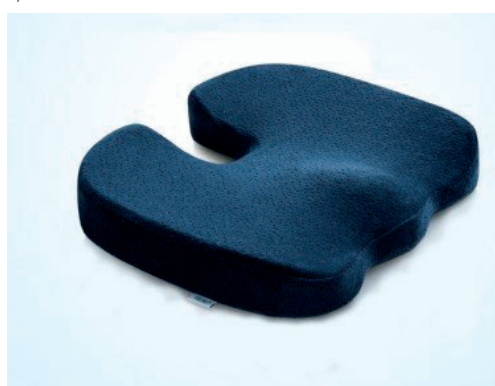

b)

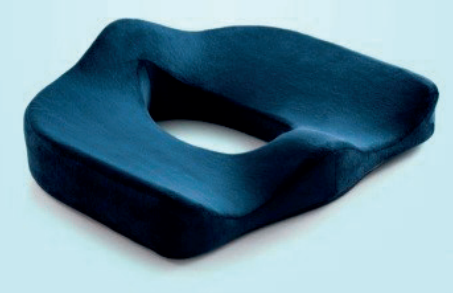

c)

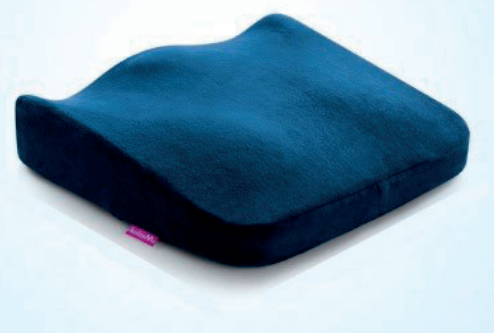

Figure 4. Supplementary seat cushions used in the experiment: a) seat cushion 1, b) seat cushion 2, c) seat cushion 3, in the study conducted on 16 volunteers in the ergonomics lab at the Department of Industrial Design, Northwestern Polytechnical University, Xi'an, China, June 6-11, 2018

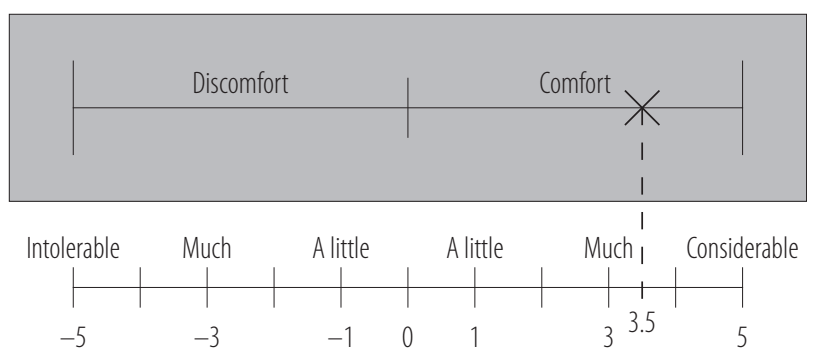

Figure 5. A visual analog scale (the upper part) and a rating example in the study conducted on 16 volunteers in the ergonomics lab at the Department of Industrial Design, Northwestern Polytechnical University, Xi'an, China, June 6-11, 2018

instructed to sit with 1 of 3 sitting postures on the chair, and then they started to type the material at a comfortable pace. The typing task was performed using typing test software (Kingsoft Typing, Beijing, China), in which the subjects typed the paragraphs shown in the screen. The pressure data started to collect data for $5 \mathrm{~min}$. The experimenter should notice the sitting posture of the subject, and inform him/her to be consistent with the required posture. There was a 1-min break before moving on to the next sitting posture. The subjects were allowed to move the buttock on the seat when changing their posture. Before recording the pressure data, the subjects could move the chair forward or backward to a proper location in order to better perform the typing task.

The order of the 3 sitting postures was randomized for each subject. After the sitting condition had finished, the subject filled out the cushion comfort questionnaire, being allowed to express any comments regarding each cushion. If the subject was not sure about the relative comfort degree of the cushion, he/she was allowed to remove the supplementary cushion and sit on the original chair again. A 5-min break was allowed before the second trial. The experimenter randomly chose 1 of 3 supplementary seat cushions and put it under the pressure mat on the seat pan. The order in which the conditions were encountered were randomized within a predetermined counterbalanced structure to control for potential order effects. The subjects were encouraged to walk around to recover before the next experimental trial. The same steps were repeated to test all 3 supplementary seat cushions.

\section{Data analysis}

Firstly, the pressure parameters, including the average pressure (AP), the mean peak pressure (MPP), the mean contact area (MCA) and the maximum pressure gradient (MaxPG), were compared for different cushions under different sitting postures. The MaxPG calculation method employed was derived from Douglas [20]. The statistical analysis was performed with SPSS Statistics 20.0 (Chicago, IL, USA). For all statistical tests, significance was set at $\mathrm{p}<0.05$. Data were tested for normality using the Shapiro-Wilk test. A 2-way ANOVA was conducted initially. The 2 factors were the sitting posture 
(forward, relaxed and upright) and the seat cushion condition (chair only, supplementary cushion 1, 2, and 3). If a significant F-test was found, post-hoc tests were conducted by pairwise comparisons. The Wilcoxon test was used to compare the mean comfort rating of the 4 seat cushion conditions. The correlation analysis was used for the relationship between pressure parameters and the subjective comfort ratings. Typical female and male pressure mappings were illustrated for pressure distribution of the different cushions.

\section{RESULTS}

Raw pressure data were exported in the format of ASCII, and a summary of pressure parameters under 4 seat cushion conditions was shown in Table 2. The pressure param- eters included AP, MPP, MCA and MaxPG. Then, the effects of the seat cushion contour and the sitting posture on these pressure parameters were analyzed, respectively.

\section{The effects of the seat cushion condition} and the sitting posture on seat pan pressure parameters Average pressure

The AP analysis revealed significant main effects of the seat cushion condition $(\mathrm{F}=18.43, \mathrm{p}<0.01)$ and the sitting posture $(\mathrm{F}=3.99, \mathrm{p}=0.02)$. There was no interaction effect between the seat cushion condition and the sitting posture on AP ( $p=0.47)$. Notably, C3 and C2 yielded the lowest and highest average pressure values under every sitting posture, respectively (Figure 6a). The average pressures of $\mathrm{C} 0$ and $\mathrm{C} 1$ were very close

Table 2. Pressure variables in the study conducted on 16 volunteers in the ergonomics lab at the Department of Industrial Design, Northwestern Polytechnical University, Xi'an, China, June 6-11, 2018

\begin{tabular}{lcccc}
\hline \multicolumn{1}{c}{ Variable } & $\begin{array}{c}\text { Average pressure } \\
{[\mathrm{mm} \mathrm{Hg}]} \\
(\mathrm{M} \pm \mathrm{SE})\end{array}$ & $\begin{array}{c}\text { Mean peak pressure } \\
{[\mathrm{mm} \mathrm{Hg}]} \\
(\mathrm{M} \pm \mathrm{SE})\end{array}$ & $\begin{array}{c}\text { Mean contact area } \\
{\left[\mathrm{cm}^{2}\right]} \\
(\mathrm{M} \pm \mathrm{SE})\end{array}$ & $\begin{array}{c}\text { Max pressure gradient } \\
{[\mathrm{kPa} / \mathrm{m}]} \\
(\mathrm{M} \pm \mathrm{SE})\end{array}$ \\
\hline $\mathrm{C} 0$ & & & & \\
$\quad$ forward & $38.79 \pm 6.68$ & $144.57 \pm 48.53$ & $1106.24 \pm 165.72$ & $87.42 \pm 39.21$ \\
relaxed & $37.68 \pm 7.68$ & $161.23 \pm 55.25$ & $1089.07 \pm 218.75$ & $71.20 \pm 31.32$ \\
upright & $42.65 \pm 16.41$ & $145.23 \pm 39.72$ & $1106.56 \pm 171.45$ & $72.42 \pm 15.04$ \\
$\mathrm{C} 1$ & & & \\
forward & $39.39 \pm 8.48$ & $112.90 \pm 35.31$ & $1145.23 \pm 118.34$ & $66.65 \pm 17.76$ \\
relaxed & $35.54 \pm 6.93$ & $106.80 \pm 27.58$ & $1153.83 \pm 155.78$ & $71.96 \pm 24.04$ \\
upright & $40.50 \pm 7.27$ & $119.57 \pm 39.08$ & $1123.18 \pm 98.80$ & $65.74 \pm 23.55$ \\
C2 & & & & \\
forward & & & $961.27 \pm 159.27$ & $127.19 \pm 42.52$ \\
relaxed & $47.18 \pm 8.14$ & $133.96 \pm 28.96$ & $978.30 \pm 144.50$ & $112.88 \pm 32.18$ \\
upright & $41.77 \pm 7.84$ & $133.37 \pm 28.38$ & $950.03 \pm 156.30$ & $132.13 \pm 45.87$ \\
C3 & $49.68 \pm 8.12$ & $143.69 \pm 25.86$ & & \\
forward & & & $1172.75 \pm 130.53$ & $58.47 \pm 20.83$ \\
relaxed & $34.27 \pm 8.54$ & $98.04 \pm 30.50$ & $1125.86 \pm 207.27$ & $54.30 \pm 22.50$ \\
upright & $33.46 \pm 5.47$ & $99.51 \pm 33.05$ & $1172.58 \pm 110.74$ & $53.35 \pm 19.34$ \\
\hline
\end{tabular}

$\mathrm{C} 0$ - original seat cushion; $\mathrm{C} 1$ - seat cushion 1; $\mathrm{C} 2$ - seat cushion 2; $\mathrm{C} 3$ - seat cushion 3. 

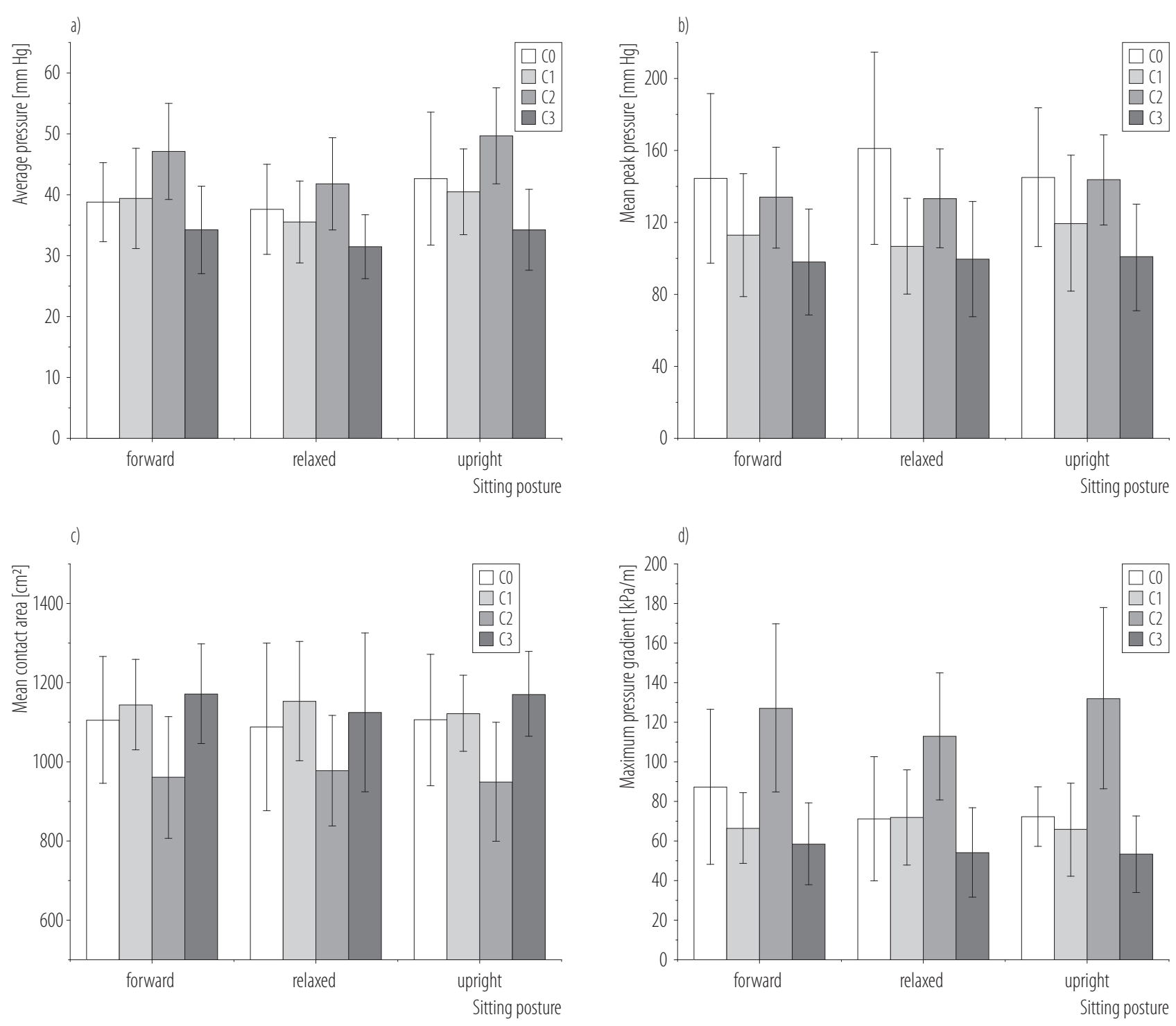

$\mathrm{C} 0$ - original seat cushion; $\mathrm{C} 1$ - seat cushion 1 ; $\mathrm{C} 2$ - seat cushion 2; $\mathrm{C} 3$ - seat cushion 3.

Figure 6. The different sitting postures under 4 seat cushion conditions: a) average pressure, b) mean peak pressure, c) mean contact area, d) maximum pressure gradient, in the study conducted on 16 volunteers in the ergonomics lab at the Department of Industrial Design, Northwestern Polytechnical University, Xi'an, China, June 6-11, 2018

under every sitting posture. The average pressure of the relaxed sitting posture was the lowest among the 3 sitting postures under every cushion condition. In addition, posthoc tests revealed that there was no significant difference $(\mathrm{p}=1.00)$ in $\mathrm{AP}$ between $\mathrm{C} 0$ and $\mathrm{C} 1$, while significant differences $(p<0.05)$ in AP were found between other pairwise seat cushion conditions.

\section{Mean peak pressure}

It was found that MPP was significantly affected by the seat cushion condition $(\mathrm{F}=1774.52, \mathrm{p}<0.01)$ while there was no significant effect of the sitting posture on $\operatorname{MPP}(p=0.65)$. There was no interaction effect between the seat cushion condition and the sitting posture on MPP $(\mathrm{p}=0.75)$. It was found that $\mathrm{C} 3$ had significantly lower 
MPP compared to other conditions (Figure 6b). The results of post-hoc tests showed that there was no significant difference between the sitting postures for MPP; however, C0 yielded significantly larger MPP than $\mathrm{C} 1$ and $\mathrm{C} 3$ $(\mathrm{p}<0.01, \mathrm{p}<0.01)$, and MPP of C2 also was significantly larger than those of $\mathrm{C} 1$ and $\mathrm{C} 3(\mathrm{p}<0.01, \mathrm{p}<0.01)$.

\section{Mean contact area}

The MCA values for 4 seat cushion conditions are shown in Figure $6 \mathrm{c}$ and they were significantly affected by the seat cushion condition $(\mathrm{F}=15.11, \mathrm{p}<0.01)$. No significant effect of the sitting posture on MCA was found $(p=0.93)$. There was no seat cushion condition $\times$ sitting posture interaction effect on MCA $(\mathrm{p}=0.96)$. The Tukey post-hoc multiple comparisons indicated that $\mathrm{C} 2$ had a significantly lower average MCA than C0 ( $p<0.01), \mathrm{C} 1$ ( $p<0.01)$ and C3 ( $p<0.01)$. No significant difference in MCA was found between the sitting postures.

\section{Maximum pressure gradient}

Figure 6d graphically portrays the results of MaxPG for each sitting posture under 4 different seat cushion conditions. It was shown that $\mathrm{C} 2$ and $\mathrm{C} 0$ had the highest and lowest MaxPG values for the 3 sitting postures, respectively. No statistically significant difference was revealed in the sitting posture $(\mathrm{F}=0.93, \mathrm{p}=0.39)$ and the seat cushion condition $\times$ sitting posture interaction effect $(\mathrm{F}=$ $0.84, p=0.54)$. There were significant differences for the 4 seat cushion conditions ( $F=46.37, p<0.01)$. More specifically, post-hoc tests revealed that MaxPG of $\mathrm{C} 2$ was significantly higher than that of other cushions (all $p<0.01$ ), and that there was a significant difference between $\mathrm{C} 0$ and $\mathrm{C} 3(\mathrm{p}<0.01)$.

\section{Subjective seat cushion condition comfort ratings}

The seat cushion comfort rating revealed people's integrated subjective perception, and it did not take the sitting posture into consideration in this study. The subjects were asked to rate the cushion comfort degree by taking the original chair as the baseline for normal comfort. Via ANOVA, the data revealed that there was a significant effect of the seat cushion condition on the subjective comfort rating $(\mathrm{F}=14.345, \mathrm{p}<0.01)$. With regard to the ranking of the cushion comfort, $\mathrm{C} 3$ had the highest subjective comfort rating (2.35), followed by $\mathrm{C} 1$ (1.65) and $\mathrm{C} 0$ (0), while $\mathrm{C} 2$ showed the lowest level of comfort rating $(-0.55)$ (Figure 7). The Wilcoxon test displayed that $\mathrm{C1}$ was ranked significantly better than $\mathrm{C} 0(\mathrm{p}<0.01)$ and $\mathrm{C} 2$ $(\mathrm{p}<0.01)$, while $\mathrm{C} 3$ was ranked significantly higher than $\mathrm{C} 0(\mathrm{p}<0.01)$ and $\mathrm{C} 2(\mathrm{p}<0.01)$. No significant difference was found between $\mathrm{C} 1$ and $\mathrm{C} 3$ ( $\mathrm{p}>0.05$ ). No effects of sex were found on the cushion comfort ratings for any of the 3 supplementary seat cushions ( $p>0.05$ ).

\section{Interface pressure distribution}

\section{for male and female subjects}

The 2 typical (female and male) subjects' surface pressure mappings extracted from the seat pan pressure mats were displayed in Figure 8. The time of pressure distribution measurement was set at 20th s, when the state of the sitting posture was already stable. Color bars showed the specific color corresponding to the pressure value. As can be seen, the seat pan had different shapes formed by the seat-body contact pressure, and it proved that the seat cushion contour was in relation to interface pressures distribution. However, the shape of the contact pressure mapping revealed no big differences among 3 sitting postures with the same cushion. In Figure 8, the coverage of high pressure values (red and orange) of $\mathrm{C} 1, \mathrm{C} 2$ and $\mathrm{C} 3$ significantly shrank for 2 subjects, compared with $\mathrm{C} 0$. The supplementary cushion increased the thickness of the seat cushion; it suggested that a thicker seat cushion might reduce the area of high pressure and even the peak pressure value.

The same situation happened in $\mathrm{C} 1$ and $\mathrm{C} 3$, but $\mathrm{C} 3 \mathrm{had}$ a smaller coverage of medium pressure (green color) in the location of the buttock than $\mathrm{C}$. The possible reason may 


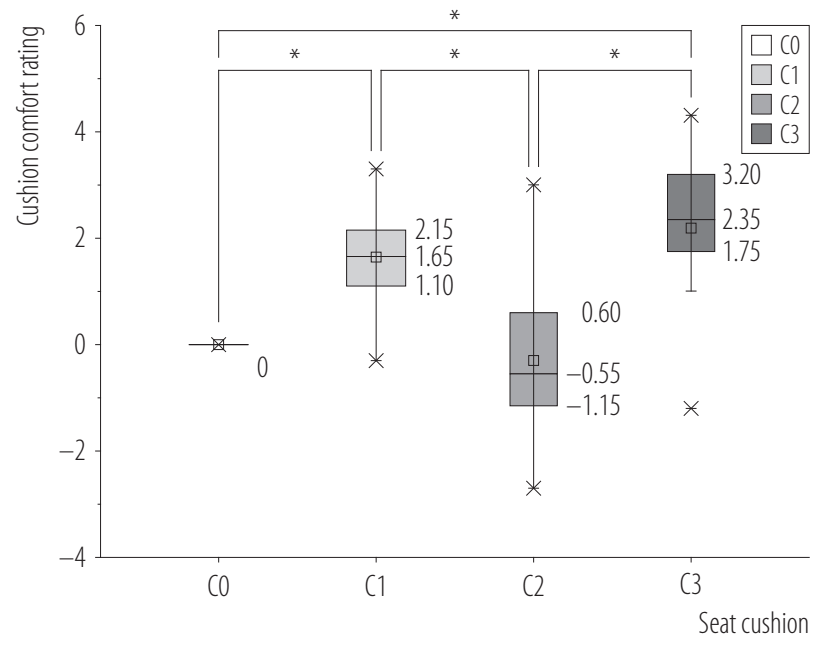

Abbreviations as in Figure 6.

* A significant difference between 2 cushion comfort ratings.

Figure 7. A box plot of cushion comfort ratings in the study conducted on 16 volunteers in the ergonomics lab at the Department of Industrial Design, Northwestern Polytechnical University, Xi'an, China, June 6-11, 2018 be that the area of the 2 buttocks in $\mathrm{C} 1$ had a slightly bigger thickness than the area of $\mathrm{C} 3$. There was a gap in the coccygeal vertebrae region on $\mathrm{C} 1$, which implies that there was no contact pressure between the cushion and the coccygeal vertebrae region. This cushion was beneficial to decrease the pain of the coccygeal vertebrae region. The contour of C2 looks like human buttocks; there was an ellipse hole in the middle of the cushion, and it yielded the worst comfort rating. As shown in Figure 8 (C1-C3) for 2 subjects, the concentration of stress happened at the edge of $\mathrm{C} 2$.

\section{Correlation analysis of pressure parameters and subjective comfort ratings}

Pearson's correlations were analyzed among the subjective comfort ratings and pressure variables. Table 3 listed the results of the statistical analysis. There were statistically significant correlations between the seat cushion com-
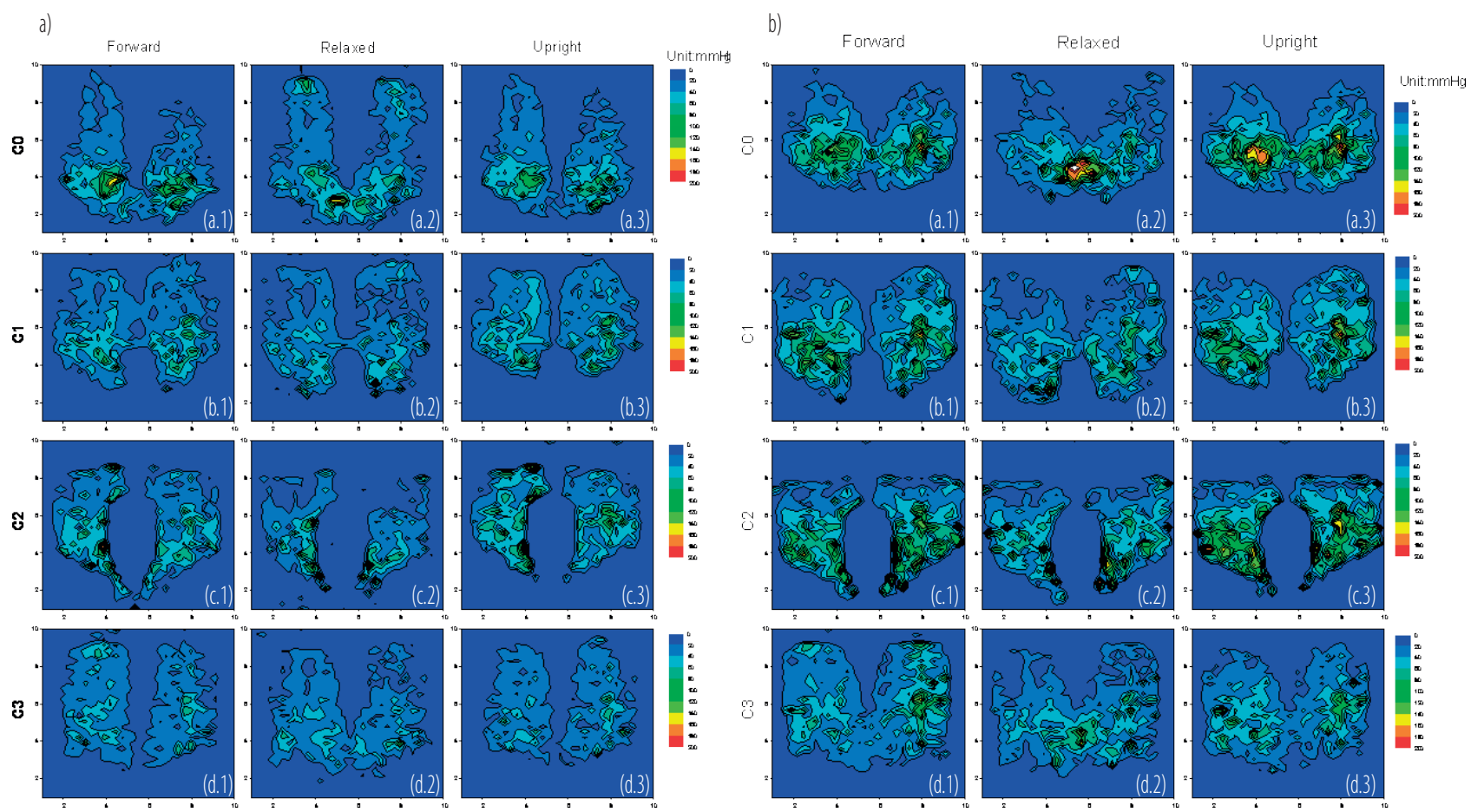

Abbreviations as in Figure 6.

Figure 8. An example of a) female and b) male pressure distributions of 3 sitting postures, under 4 seat cushion conditions, in the study conducted on 16 volunteers in the ergonomics lab at the Department of Industrial Design, Northwestern Polytechnical University, Xi'an, China, June 6-11, 2018 
fort rating and AP, MPP and MCA, while no significant correlation was found between the seat cushion comfort rating and MaxPG ( $\mathrm{p}>0.05$ ). More specifically, MCA (correlation coefficient $=0.454$ ) was positively correlated with the subjective comfort rating, while MPP (correlation coefficient $=-0.424)$ and AP (correlation coefficient = -0.289 ) were significantly negatively correlated with the subjective comfort rating. Additionally, MaxPG was significantly correlated with AP (correlation coefficient = 0.405 ) and MPP (correlation coefficient $=0.595$ ).

\section{DISCUSSION}

In this study, the authors analyzed how different seat cushions and sitting postures within a seated work environment affected the seat pan surface pressure distribution and comfort perception. Then, they investigated the correlation between seat cushion contours and sitting postures, perceived comfort during short-term sitting in office work.

\section{The effect of the seat cushion contour and sitting postures on pressure distribution}

Three different supplementary seat cushion contours formed 3 pressure mappings with the user on the seat. It was proven that the seat cushion contour had an effect on pressure distribution. The feature of the hole in the center of $\mathrm{C} 2$ is a bad design, as the concentration of stress was found to occur at the edge of the hole on $\mathrm{C} 2$ for 2 subjects (Figure 8 [C1-C3]). The MaxPG values of $\mathrm{C} 2$ were located at the edge of the hole. This could explain why $\mathrm{C} 2$ had the lowest comfort rating. The possible reason was that the contour of the seat cushion cannot conform to the shape of the subject' buttock, when he/she sat on it [21]. Although the area in the center of the seat pan is

Table 3. A correlation analysis of pressure parameters and subjective comfort ratings in the study conducted on 16 volunteers in the ergonomics lab at the Department of Industrial Design, Northwestern Polytechnical University, Xi'an, China, June 6-11, 2018

\begin{tabular}{|c|c|c|c|c|c|}
\hline \multirow{2}{*}{ Variable } & \multicolumn{5}{|c|}{ Correlation } \\
\hline & 1 & 2 & 3 & 4 & 5 \\
\hline \multicolumn{6}{|c|}{ 1. Seat cushion comfort rating } \\
\hline Pearson's correlation & 1 & $-0.289^{*}$ & $-0.424^{* *}$ & $0.454^{* *}$ & -0.173 \\
\hline $\mathrm{p}$ & & 0.047 & 0.003 & 0.001 & 0.240 \\
\hline \multicolumn{6}{|l|}{ 2. Average pressure } \\
\hline Pearson's correlation & & 1 & $0.386^{* *}$ & -0.089 & $0.405^{* *}$ \\
\hline $\mathrm{p}$ & & & 0.007 & 0.547 & 0.004 \\
\hline \multicolumn{6}{|l|}{ 3. Mean peak pressure } \\
\hline Pearson's correlation & & & 1 & $-0.767^{* *}$ & $0.595^{* *}$ \\
\hline $\mathrm{p}$ & & & & 0.000 & 0.000 \\
\hline \multicolumn{6}{|l|}{ 4. Mean contact area } \\
\hline Pearson's correlation & & & & 1 & 0.186 \\
\hline $\mathrm{p}$ & & & & & 0.205 \\
\hline \multicolumn{6}{|l|}{ 5. Max pressure gradient } \\
\hline Pearson's correlation & & & & & 1 \\
\hline $\mathrm{p}$ & & & & & \\
\hline
\end{tabular}

\footnotetext{
* Significant (2-tailed) correlations at the level of $0.05 ; * *$ Significant (2-tailed) correlations at the level of 0.01 .
} 
usually not contacted with the thigh, this part still bears the shear load from the adjacent area.

There are some differences in the pelvic shape and size distributions, as well as differences in the size and shape of the ischial tuberosities. So, the seat cushion needs to be "customized" and should consider the anthropometric data of individual users, which contribute to forming the appropriate contour [22]. Seat pan support to the pelvis should be provided under, behind, in front of, or from the sides. Extra support can be provided by contours around the buttocks and thighs. For $\mathrm{C} 1$ or $\mathrm{C} 3$, the 2 peak pressure zones (red and orange colors) which were beneath the ischial tuberosities were dramatically decreased, compared with C0 (Figure 8). Based on a linear relationship between the applied force and the compression ratio, Diebschlag [23] recommended polyurethane foam for the upholstery and cushions . The proper foam minimizes the concentration of pressure beneath the tuberosities and achieves a more suitable pressure distribution.

A greater uniformity on pressure distribution and a lower peak pressure implied an improvement of the user's comfort on the seat [24]. From this perspective, C3 and C1 had better pressure distributions and comfort perceptions than $\mathrm{C} 0$ for the upright sitting posture as per Figure 8. The mean peak pressure of $\mathrm{C} 1$ and $\mathrm{C} 3$ was decreased by $17.7 \%$ and $30.8 \%$ for the upright sitting posture, respectively (Table 2). A possible explanation for this finding is that a thicker support in the buttock region might decrease the peak pressure on the seat pan. Red color (Figure 8 [a.3]) around the ischial bones changed into green color denoting lower pressure (Figure 8 [b.3] [d.3]). Ebe and Griffin [25] found that the subjects evaluated the static seat feeling based on the pressure around the ischial bones, so cushions with higher pressures around this area were evaluated as offering less comfort.

When an individual is in the forward or upright sitting posture, the gravity load of the upper body is transmitted to the seat via the protuberances on the base of the pelvis, the ischial tuberosities, and the peak pressure occurs in the place contacted with the ischial tuberosities of the buttock. However, when an individual assumes a relaxed sitting posture, the location of peak pressure shifts from the ischial tuberosities to the sacrum coccyx at the rear of the ischia. No differences in MPP, MCA and MaxPG were found between the sitting postures, which implies that the sitting posture has no effect on the MPP, MCA and MaxPG. From the above discussion and from Figure 8, it can be concluded that the sitting posture had an impact on the location of peak pressure.

Based on geometry and the observed differences of AP, MPP, MCA and MaxPG, it was found that the seat cushion contour influenced the pressure parameters of the seat pan. Therefore, seat cushion contour design appears to have a great impact on seat pan interface pressure parameters.

\section{The relationship between the subjective cushion comfort rating and pressure parameters}

The results of a bivariate correlation analysis demonstrated that significant relationships exist between the subjective comfort rating and the objective surface pressure measures used in this study. The subjective comfort rating was significantly negatively correlated with AP and MPP. Previous studies [26,27] revealed a relationship between pressure distribution and comfort/discomfort assessments. De Looze et al. [28], performing a literature review, showed that there were several studies indicating that a good pressure distribution in the seat cushion was related to the comfort experience [28]. Noro et al. [29] found that comfort was related to low peak pressures and high contact areas of the seat pan. Zemp et al. [30] reviewed the body of literature regarding the seat comfort determined through pressure measurements and concluded that the peak pressure on the seat pan, the pressure distribution on the backrest and the pressure pattern changes (seat pan and backrest) all appeared to be reliable measures for quantifying comfort or discomfort. 
Although no significant correlation existed between MaxPG and the comfort rating, $\mathrm{C} 2$ with the largest MaxPG had the lowest the comfort rating. It can, therefore, be concluded that MaxPG is an indicator to distinct bad pressure distribution. The correlations between pressure parameters and comfort ratings provide further support for the relationship between the seat cushion contour and comfort during seated work. The location of peak pressure is a good indicator to distinct pressure distribution. The findings obtained through this analysis further confirm and extend the findings previously available in literature.

\section{Limitation and future work}

It has to be acknowledged that there are some limitations of the current study. This study involved a small sample of pain-free participants, without an a priori power calculation of the sample size, necessary to detect differences between seat cushions. Furthermore, the duration of exposure was relatively short. Both the short duration and the small sample size reduce the likelihood of finding significant differences between the 4 seat cushion conditions. Notwithstanding its limitation, this study does suggest some significant differences in seat cushion contours. Differences in the posture and comfort perception may be even more pronounced during longer sitting exposures in a larger sample of participants with LBP. An analysis of more dynamic seated tasks is warranted. Future work should focus on verifying the relationship between specific features of cushion contours and pressure parameters.

\section{CONCLUSIONS}

This study provided new insights into the effects of seat cushion contours on biomechanical variables as well as the subject's comfort perception in seated office work. Seat cushions with distinctive contour lines do not always have a larger contact area and more perceived sitting comfort, compared with common flat seat cushions. The final conclusion drawn from this study is that both the seat cushion contour and the sitting posture result in significant pressure distribution differences, while the seat cushion contour additionally results in changes in pressure parameters, and the sitting posture affects the location of peak pressure.

In addition, pressure parameters, including AP and MPP on the seat pan, were identified that were correlated with the subjective cushion comfort ratings. A statistically significant relationship between pressure parameters and comfort perception has been reported in a lot of existing studies. Therefore, pressure data are suggested as an appropriate indicator for assessing short-term comfort of a seat cushion, reflecting seat support properties and the distribution of body load, which may appear useful in the indirect objective assessment of other types of seating surfaces with design differences.

Furthermore, considering body interface pressure distribution and pressure parameters, the supplementary cushion design is a good way to strengthen the user's comfort while seated. However, seat cushion contour design should fit with the surface of an individual's thigh and buttock. A bad seat cushion contour (e.g., C3) is likely to decrease the sitting comfort. It is concluded that the incorporation of pressure measurements, besides the subjective comfort ratings, in the process of seat cushion design, would be valuable. Understanding the seat cushion contour impact on comfort perception also provided implications on the approaches to avoid the discomfort factor in seat cushion contour design. Overall, this study contributed to the research on the characteristics of surface pressure changes induced by seat cushion contours in short-term seated work, which enhanced the knowledge on the seat comfort theory.

\section{ACKNOWLEDGMENTS}

The authors would like to thank the participating individuals for their time and efforts. 


\section{REFERENCES}

1. Lis AM, Black KM, Korn H, Nordin M. Association between sitting and occupational LBP. Eur Spine J. 2007;16(2):283-98, https://doi.org/10.1007/s00586-006-0143-7.

2. De Carvalho DE, Soave D, Ross K, Callaghan JP. Lumbar Spine and Pelvic Posture Between Standing and Sitting: A Radiologic Investigation Including Reliability and Repeatability of the Lumbar Lordosis Measure. J Manipulative Physiol Ther. 2010;33(1):48-55, https://doi.org/10.1016/j.jmpt.2009.11.008.

3. O'Sullivan PB, Grahamslaw KM, Kendell M, Lapenskie SC, Möller NE, Richards KV. The effect of different standing and sitting postures on trunk muscle activity in a pain-free population. Spine. 2002;27(11):1238-44, https://doi.org/10.1097/0000 7632-200206010-00019.

4. Pynt J, Higgs J, Mackey M. Seeking the optimal posture of the seated lumbar spine. Physiother Theory Pract. 2001;17(1):5-21, https://doi.org/10.1080/09593980151143228.

5. Ellegast RP, Kraft K, Groenesteijn L, Krause F, Berger H, Vink P. Comparison of four specific dynamic office chairs with a conventional office chair: Impact upon muscle activation, physical activity and posture. Appl Ergon. 2012;43:296-307, https://doi.org/10.1016/j.apergo.2011.06.005.

6. Zemp R, Taylor WR, Lorenzetti S. Seat pan and backrest pressure distribution while sitting in office chairs. Appl Ergon. 2016;53(1):1-9, https://doi.org/10.1016/j.apergo.2015.08.004.

7. Munoz F, Rougier PR. Estimation of centre of gravity movements in sitting posture: Application to trunk backward tilt. J Biomech. 2011;44(9):1771-5, https://doi.org/10.1016/j.jbiomech.2011.04.008.

8. Wong AYL, Chan TPM, Chau AWM, Tung Cheung H, Kwan KCK, Lam AKH, et al. Do different sitting postures affect spinal biomechanics of asymptomatic individuals? Gait Posture. 2019;67:230-5, https://doi.org/10.1016/j.gaitpost.2018.10.028.

9. O'Sullivan K, McCarthy R, White A, O'Sullivan L, Dankaerts W. Lumbar posture and trunk muscle activation during a typing task when sitting on a novel dynamic ergonomic chair. Ergonomics. 2012;55:1586-95, https://doi.org/10.1080/0 0140139.2012.721521.
10. Munoz F, Rougier PR. Estimation of centre of gravity movements in sitting posture: Application to trunk backward tilt. J Biomech. 2011;44(9):1771-5, https://doi.org/10.1016/j.jbiomech.2011.04.008.

11. Cascioli V, Liu Z, Heusch AI, McArthy PW. Settling down time following initial sitting and its relationship with comfort and discomfort. J Tissue Viabilit. 2011;20(4):121-9, https:// doi.org/10.1016/j.jtv.2011.05.001.

12. Gil-Agudo A, De la Peña-González A, Del Ama-Espinosa A, Pérez-Rizo E, Díaz-Domínguez E, Sánchez-Ramos A. Comparative study of pressure distribution at the user-cushion interface with different cushions in a population with spinal cord injury. Clin Biomech. 2009;24:558-63, https://doi. org/10.1016/j.clinbiomech.2009.04.006.

13. Sprigle S, Wootten M, Sawacha Z, Theilman G. Relationships among cushion type, backrest height, seated posture, and reach of wheelchair users with spinal cord injury. J Spinal Cord Med. 2003;26:236-43, https://doi.org/10.1080/1079 0268.2003.11753690.

14. Ragan R, Kernozek TW, Bidar M, Matheson JW. Seatinterface pressures on various thicknesses of foam wheelchair cushions: A finite modeling approach. Arch Phys Med Rehabil. 2002;83:872-5, https://doi.org/10.1053/apmr. 2002.32677 .

15. Jan Y-K, Jones MA, Rabadi MH, Foreman RD, Thiessen A. Effect of Wheelchair Tilt-in-Space and Recline Angles on Skin Perfusion Over the Ischial Tuberosity in People With Spinal Cord Injury. Arch Phys Med Rehabil. 2010;91:175864, https://doi.org/10.1016/j.apmr.2010.07.227.

16. Vos GA, Congleton JJ, Steven Moore J, Amendola AA, Ringer L. Postural versus chair design impacts upon interface pressure. Appl Ergon. 2006;37(5):619-28, https://doi. org/10.1016/j.apergo.2005.09.002.

17. Mooney V, Einbund MJ, Rogers JE, Stauffer ES. Comparison of pressure distribution qualities in seat cushions. Bull Prosthet Res. 1971;10(15):129-43.

18. Tasker LH, Shapcott NG, Watkins AJ, Holland PM. The effect of seat shape on the risk of pressure ulcers using 
discomfort and interface pressure measurements. Prosthet Orthot Int. 2014;38(1):46-53, https://doi.org/10.1177/03093 64613486918.

19. Noro K, Fujimaki G, Kishi S. A Theory on Pressure Distribution and Seat Discomfort. In: Vink P, Klaus B, editors. Comfort and design. Boca Raton: CRC Press; 2004. p. 33-9.

20. Hobson DA. Comparative effects of posture on pressure and shear at the body-seat interface. J Rehabil Res Dev. 1992;29(4):21, https://doi.org/10.1682/JRRD.1992.10.0021.

21. Cascioli V, Liu Z, Heusch A, McCarthy PW. A methodology using in-chair movements as an objective measure of discomfort for the purpose of statistically distinguishing between similar seat surfaces. Appl Ergon. 2016;54:100-9, https://doi.org/10.1016/j.apergo.2015.11.019.

22. Hostens I, Papaioannou G, Spaepen A, Ramon H. Buttock and back pressure distribution tests on seats of mobile agricultural machinery. Appl Ergon. 2001;32(4):347-55, https:// doi.org/10.1016/S0003-6870(01)00013-8.

23. Diebschlag W, Heidinger F, Kurz B, Heiberger R. Recommendation for Ergonomic and Climatic Physiological Vehicle Seat Design. J Cell Plast. 1989;25(2):125-37, https://doi. org/10.1177/0021955X8902500203.

24. Da Silva L, Bortolotti SLV, Campos ICM, Merino EAD. Comfort model for automobile seat. Work. 2012;41(Suppl 1): 295-302.
25. Ebe K, Griffin MJ. Factors affecting static seat cushion comfort. Ergonomics. 2001;44(10):901-21, https://doi.org/10. 1080/00140130110064685.

26. Fujimaki G, Mitsuya R. Study of the seated posture for VDT work. Displays. 2002;23(1):17-24, https://doi.org/10.1016/S01 41-9382(02)00005-7.

27. López-Torres M, Porcar R, Solaz J, Romero T. Objective firmness, average pressure and subjective perception in mattresses for the elderly. Appl Ergon. 2008;39(1):123-30, https://doi.org/10.1016/j.apergo.2006.11.002.

28. De Looze MP, Kuijt-Evers LFM, Van Dieën J. Sitting comfort and discomfort and the relationships with objective measures. Ergonomics. 2003;46(10):985-97, https://doi.org/ 10.1080/0014013031000121977.

29. Noro K, Naruse T, Lueder R, Nao-iN, Kozawa M. Application of Zen sitting principles to microscopic surgery seating. Appl Ergon. 2012;43(2):308-19, https://doi.org/10.1016/j.apergo. 2011.06.006.

30. Zemp R, Taylor WR, Lorenzetti S. Are pressure measurements effective in the assessment of office chair comfort/discomfort? A review. Appl Ergon. 2015;48:273-82, https://doi. org/10.1016/j.apergo.2014.12.010.

This work is available in Open Access model and licensed under a Creative Commons Attribution-NonCommercial 3.0 Poland License - http://creativecommons.org/ licenses/by-nc/3.0/pl/deed.en. 